\title{
Coexisting protruding osteocyte and arachnoid cyst mimicking spinal cord herniation in a patient with Brown Sequard syndrome
}

jinxing li ( $\sim$ lijinxing@163.com )

Linyi People's Hospital https://orcid.org/0000-0002-8625-5009

Toru Sasamori

Sapporo Azabu Neurosurgical Hospital

Kazutoshi Hida

Sapporo Azabu Neurosurgical Hospital

\section{Case report}

Keywords: Brown-Sequard syndrome, spinal cord herniation, arachnoid cyst, osteophyte

Posted Date: September 8th, 2021

DOl: https://doi.org/10.21203/rs.3.rs-814285/v1

License: (1) (i) This work is licensed under a Creative Commons Attribution 4.0 International License.

Read Full License 


\section{Abstract}

This 68-year-old man presented with progressive spastic paraparesis of 2-month duration. The diagnosis was Brown-Sequard syndrome(BSS). Magnetic resonance imaging (MRI) revealed ventral displacement of the spinal cord at Th 7-8. The spinal cord deformity was dominant on the left side. He underwent surgery under the preoperative diagnosis of spinal cord herniation at Th 7-8. Intraoperatively we detected an arachnoid cyst and an osteophyte that compressed the spinal cord at Th 7-8 dorsally and ventrally rather than spinal cord herniation. Postoperative MRI showed successful spinal cord decompression. His neurological findings improved remarkably just after surgery. Although the misdiagnosis of spinal hernia in the actual presence of arachnoid cysts has been reported, ours is the first case of both, a lateralized osteophyte and an arachnoid cysts mimicking spinal cord herniation.

\section{Introduction:}

Idiopathic spinal cord herniation (ISCH) eliciting progressive myelopathy was first reported in $1974 .{ }^{1}$ It is a rare disease now easily diagnosed on magnetic resonance imaging (MRI) scans. ${ }^{2}$ More than 170 cases of ISCH have been reported to date. ${ }^{3}$ Most of these were initially misdiagnosed as arachnoid cysts. ${ }^{4}$ While our preoperative diagnosis was ISCH, additional studies showed that our patient's SSB was due to the co-presence of a protruding osteophyte and an arachnoid cyst. Our search of the literature found no similar cases. Ours is the first case documenting the presence of a thoracic arachnoid cyst and a lateralized osteophyte mimicking spinal cord herniation. ${ }^{5}$

\section{Case Report:}

A 68-year-old man with a 2-month history of progressive gait disturbance was referred to our hospital on November 2, 2019. Neurological examination revealed left-dominant spastic paraparesis, gait disturbance, and right-dominant sensory disturbance indicative of Brown-Sequard syndrome (BSS). Magnetic resonance imaging (MRI) showed compression and deformity of the spinal cord with a shift to the ventral side at the level of Th 7-8. The dorsal cerebrospinal fluid (CSF) space in the spinal cord was enlarged, suggesting a coexisting arachnoid cyst. (Fig. 1)Under a preoperative MRI diagnosis of spinal cord herniation he underwent surgery on December 20, 2019. Laminectomy was performed at Th 7-8. Ultra-sonography revealed ventral spinal cord shift. After opening the dura mater we found a large arachnoid cyst located dorsally. Methylene-blue was injected into the cyst, its arachnoid membrane was peeled from the surrounding spinal cord, and the cyst was completely excised. (Fig. 2) Intraoperative inspection of the ventral side of the spinal cord denied spinal cord herniation. However, we observed the protrusion of a left lateralized osteophyte through the ventral dura mater. (Fig. 3) We concluded that the arachnoid cyst and osteophyte were responsible for the patient's BSS.

\section{Discussion:}


ISCH results from the spontaneous displacement of the thoracic cord through an anterior dural defect. Clinical symptoms tend to depend on the herniation site. ${ }^{6}$ Early clinical manifestations include numbness and a pin-prick sensation in the lower limbs with progressive gait disturbance and incontinence. ${ }^{7}$ More than half of patients present with BSS. ${ }^{8}$ In our patient, sagittal MRI scans showed that the spinal cord protruded ventrally at Th 7-8 especially on the right side. The CSF space behind the spinal cord was significantly enlarged, a diagnostic criterion for a spinal hernia. ${ }^{8}{ }^{9} \mathrm{After}$ removing the arachnoid cyst we explored the ventral side of the spinal cord and found neither a dural defect nor spinal herniation. We did, however, detect a right dominant osteophyte at the level of Th 7-8. Therefore, we speculate that the presence of the dorsal cyst and the osteophyte resulted in our misdiagnose of spinal cord herniation.Our experience with this patient alerts to the need for a differential diagnosis that considers not only neurological- but also MRI findings when spinal cord herniation is suspected.

\section{Conclusions:}

We report a rare patient whose coexisting spinal arachnoid cyst and osteophyte at the same thoracic level mimicked spinal cord herniation. This type of pathology must be considered in patients manifesting BSS.

\section{Declarations:}

\section{ETHICS APPROVAL AND CONSENT TO PARTICIPATE}

- Ethics committee $₫ 2021$ Azabunougek03囚approved the study.

•CONSENT FOR PUBLICATION

Patient Consent-The patient has consented to the submission of the case report for submission to the journal.

\section{-AVAILABILITY OF DATA AND MATERIALS}

Data sharing not applicable to this article as no datasets were generated or analysed during the current study.

\section{•COMPETING INTERESTS}

The authors declare that they have no competing interests.

•FUNDING

The authors report no conflict of interest concerning the materials or methods used in this study or the findings specified in this paper.

•AUTHORS' CONTRIBUTIONS 
LJ participated in the design of the study and drafted the manuscript. TS edited the images. HK conceived of the study, and participated in its design and coordination and helped to draft the manuscript. All authors read and approved the final manuscript.

\section{-ACKNOWLEDGEMENTS}

The first author thanks Professors Heng Xueyuan and Zhang Yubin for their constant encouragement and guidance, Ursula Petralia for editorial assistance, and his family, friends, and colleagues for their support.

\section{•AUTHORS' INFORMATION}

Li Jinxing, Department of Neurosurgery, Linyi People's Hospital affiliated with Guangzhou University of Chinese Medicine区Linyi, Shandong, P.R. China

Corresponding Author's Email: lijinxing@163.com

FAXヌ86-0539-8019169

Kazutoshi HIDA囚Department of Neurosurgery, Sapporo Azabu Neurosurgical Hospital, Hokkaido囚Japan Corresponding Author's Email: kazuhida@azabunogeka.or.jp

FAX:011-731-0559

\section{References:}

1. Wortzman G, Tasker RR, Rewcastle NB, Richardson JC, Pearson FG. Spontaneous incarcerated herniation of the spinal cord into a vertebral body: a unique cause of paraplegia. Case report. $J$ Neurosurg. 1974;41:631-5.

2. Saito T, Anamizu Y, Nakamura K, Seichi A. Case of idiopathic thoracic spinal cord herniation with a chronic history: a case report and review of the literature. J Orthop Sci. 2004;9:94-8.

3. Randhawa PS, Roark C, Case D, Seinfeld J. Idiopathic Spinal Cord Herniation Associated With a Thoracic Disc Herniation: Case Report, Surgical Video, and Literature Review. Clin Spine Surg. 2020;33(6):222-9.

4. Shin JH, Krishnaney AA. Idiopathic ventral spinal cord herniation: a rare presentation of tethered cord. Neurosurg Focus. 2010;29:E10.

5. Haber MD, Nguyen DD, Li S. Differentiation of idiopathic spinal cord herniation from CSF-isointense intraspinal extramedullary lesions displacing the cord. Radiographics. 2014;34:313-29.

6. Barrenechea IJ, Lesser JB, Gidekel AL, Turjanski L, Perin NI. Diagnosis and treatment of spinal cord herniation: a combined experience. J Neurosurg Spine. 2006;5:294-302. 
7. Sasani M, Ozer AF, Vural M, Sarioglu AC. Idiopathic spinal cord herniation: case report and review of the literature. J Spinal Cord Med. 2009;32:86-94.

8. Summers JC, Balasubramani YV, Chan PC, Rosenfeld JV. Idiopathic spinal cord herniation: Clinical review and report of three cases. Asian J Neurosurg. 2013;8:97-105.

9. Sadek AR, Nader-Sepahi A. Idiopathic thoracic intravertebral spinal cord herniation. Br J Neurosurg. 2018;32:297-8.

\section{Figures}

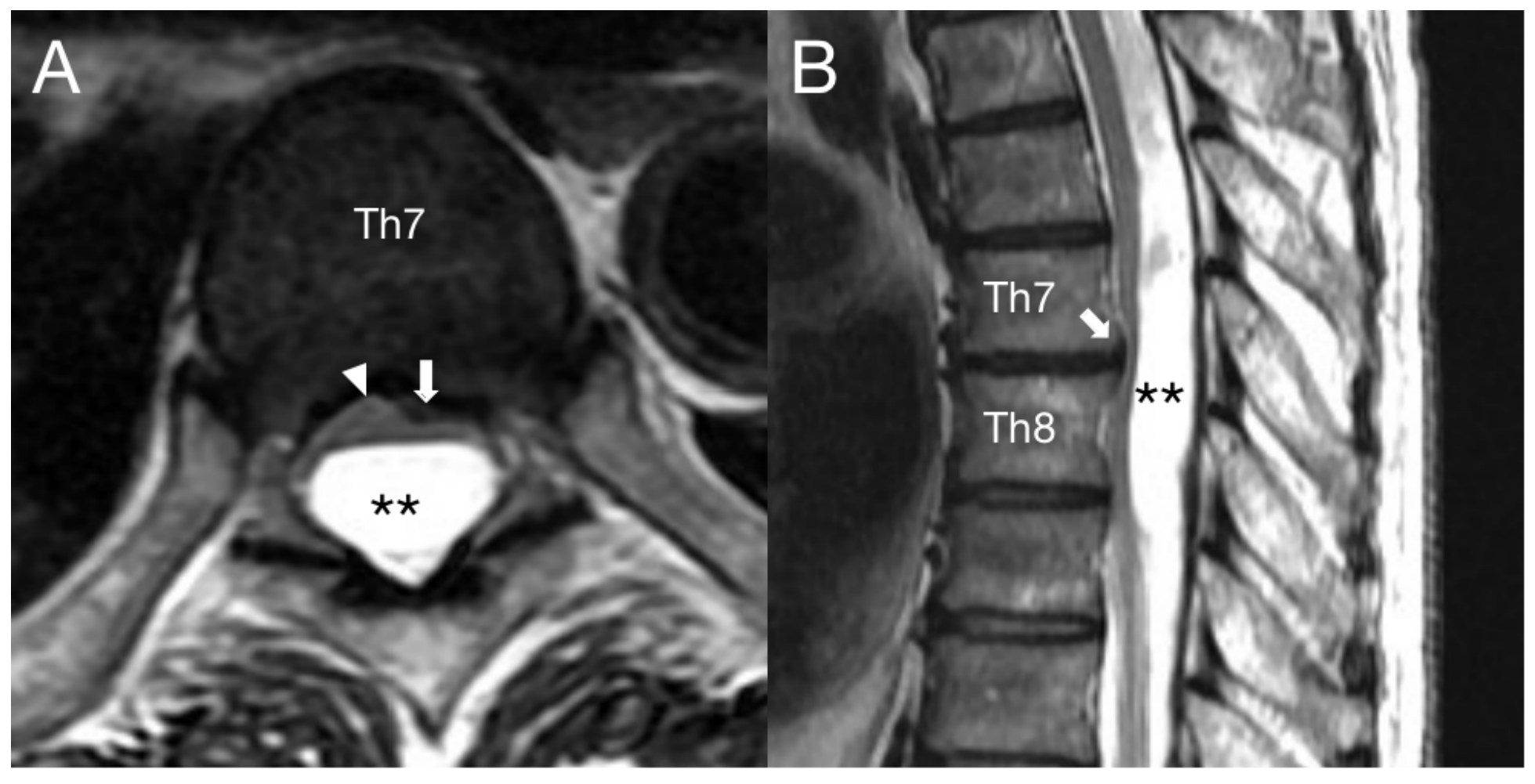

Figure 1

Axial (A) and sagittal (B) T2-weighted images of the thoracic spine demonstrating anterior displacement of the spinal cord mimicking spinal cord herniation (white triangle). Note posterior compression at Th 7 8 (white arrow) and enlargement of the dorsal CSF space. The intraoperative diagnosis was arachnoid cyst (black asterisk). 


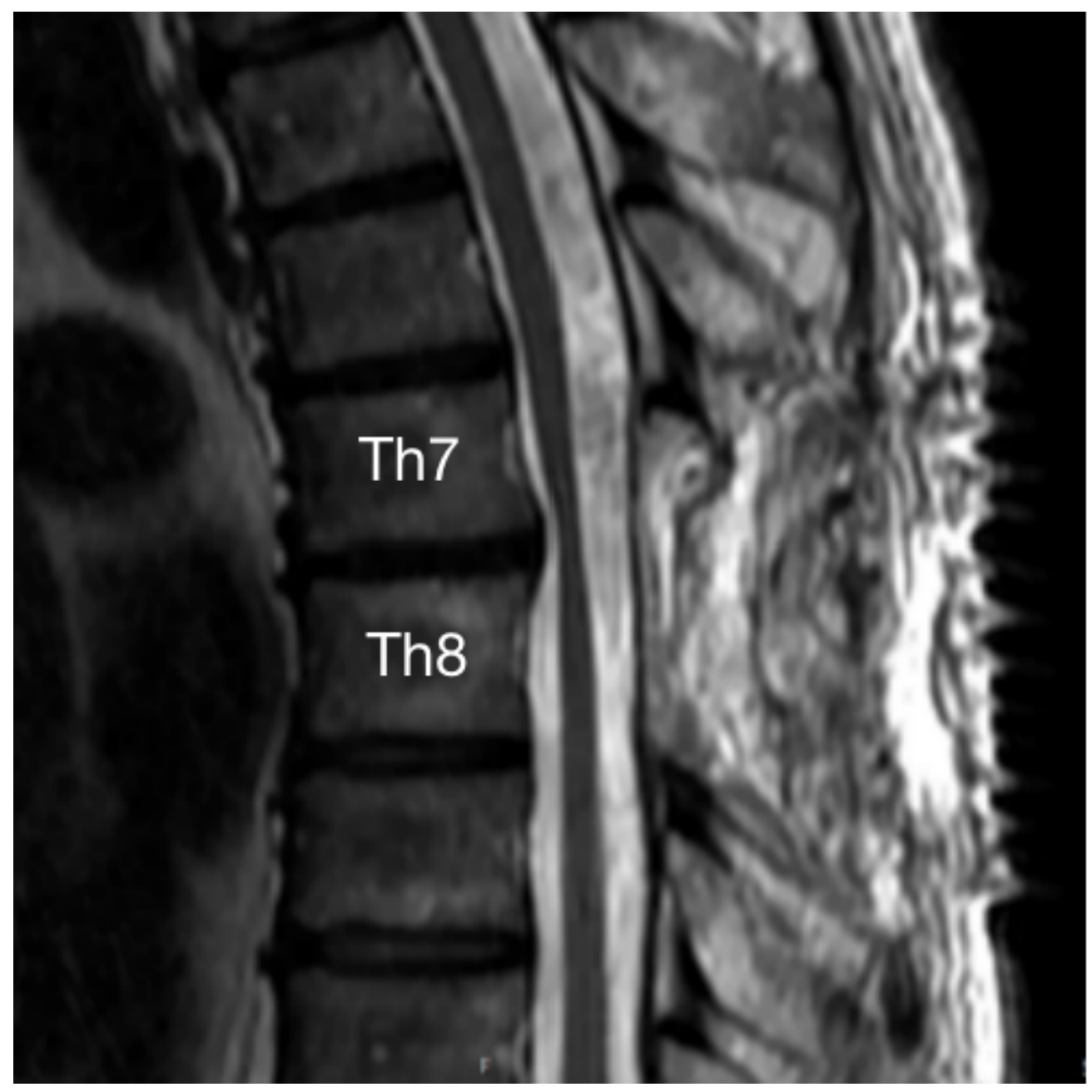

\section{Figure 2}

Postoperative sagittal T2-weighted image of the thoracic spine confirming complete excision of the arachnoid cyst and decompression of the spinal cord. 


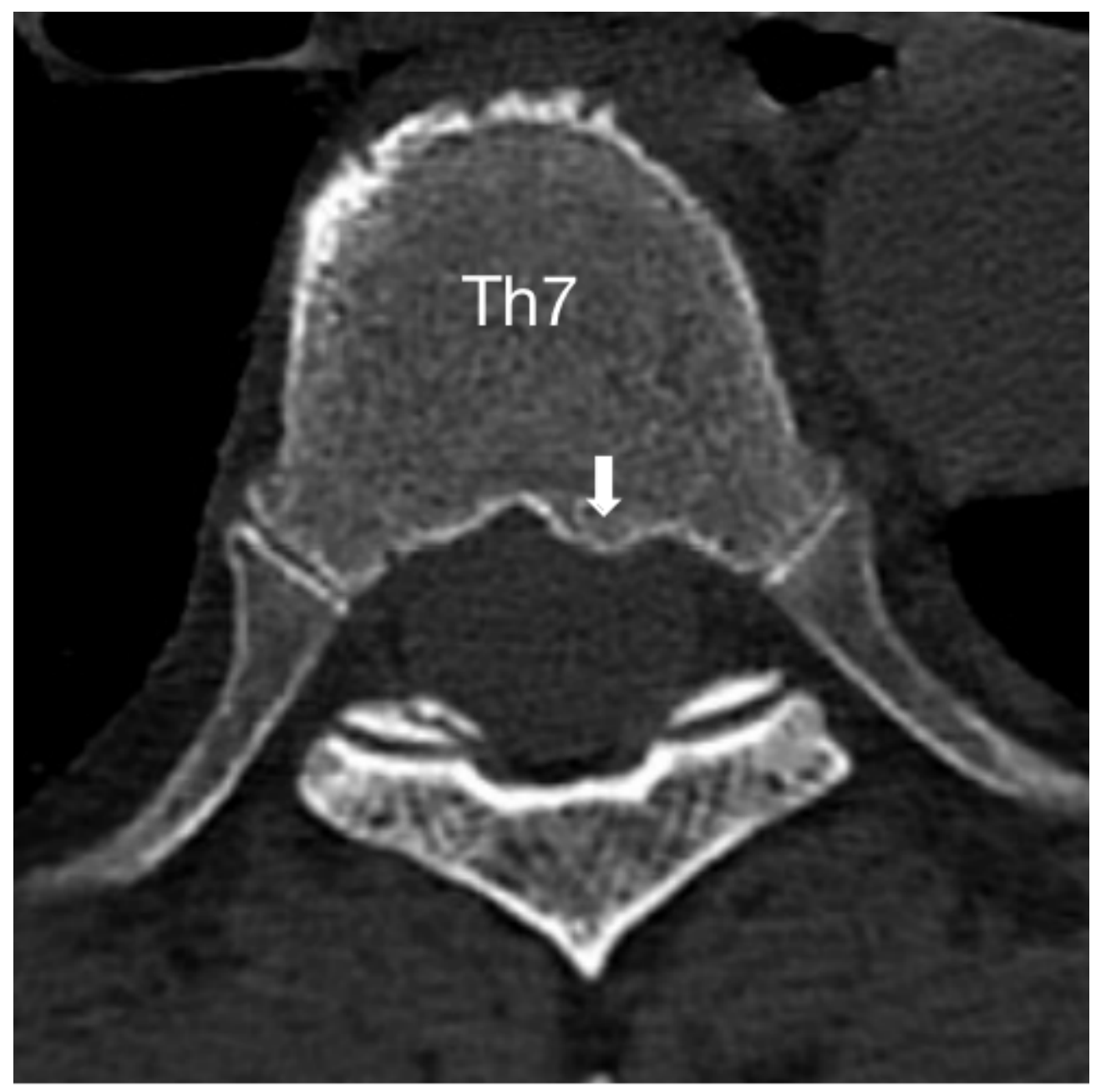

\section{Figure 3}

Axial CT scan of the thoracic spine demonstrating a left-dominant osteophyte at the Th 7 level. Its presence confirms our postoperative diagnosis of Brown-Sequard syndrome. 